\title{
Effect of Al Addition on the Microstructural Evolution of
}

\section{Equiatomic CoCrFeMnNi alloy}

\author{
Jitesh Kumar ${ }^{1}$, Nirmal Kumar ${ }^{1}$, Smarajeet Das ${ }^{2}$, N.P. Gurao ${ }^{1}$ and Krishanu Biswas ${ }^{1 *}$ \\ ${ }^{1}$ Department of Material Science \& Engineering, Indian Institute of Technology Kanpur -
} 208016, India

${ }^{2}$ Department of Metallurgical and Materials Engineering, National Institute of Technology, Rourkela-769008, Odisha, India

\section{Abstract}

The present investigation reports the effect of Aluminium-addition on the microstructural evolution in the equiatomic CoCrFeMnNi high entropy alloy. Aluminium was added to the alloy in varying quantity $(0 \leq \mathrm{Al} \leq 10$ at. $\%)$ using the vacuum arc melting technique, and phase formation have been probed using X-ray diffraction, scanning electron microscopy and transmission electron microscopy. The results indicate that the FCC phase in the alloy remains unaltered up to $\mathrm{Al}$ of 5 at.\%. The higher amount of $\mathrm{Al}$ addition leads to the precipitation of $\mathrm{B} 2 \mathrm{Al}(\mathrm{Ni}, \mathrm{Cr})$ in the $\mathrm{FCC}$ matrix. For $\mathrm{Al} \geq 7 \%$, typical phase separated microstructure consisting of FCC, and B2 phases have been observed. The microstructural changes lead to hardness variation from 1.3 to $2.2 \mathrm{GPa}$, mainly due to precipitation and solute solution hardening of FCC phase. For FCC phase, Al atoms being smaller in size can cause and lead to lattice distortion and improve yield strength. The results have been explained by detailed thermodynamical analysis using HEA3 database.

Keywords: High entropy alloy, Cantor alloy, Microstructure, TEM

E mail-kbiswas@iitk.ac.in, Phone - +91-512-2596184, Fax-+91-512-2597505 


\section{Introduction}

In last 15 years, research and development of the novel multicomponent multi-principle alloys have matured from the perspective alloy design with emphasis on engineering novel microstructure to obtain unique properties ${ }^{1}$. These alloys, popularly known HEAs (high entropy alloys) exhibit an excellent combination of properties, providing impetus to novel alloy development with single or multiphase microstructure. Although these alloys contain 5 or more components, they show FCC; BCC or combination of FCC/BCC solid solution phase in the mixture, devoid of brittle intermetallic compounds (IMCs)[1-4]. One such important alloy system in equiatomic CoCrFeMnNi, popularly known as Cantor alloy, named after the discoverer of the alloy $[5,6]$. It shows FCC solid solution $(a=0.33605 \mathrm{~nm})$, exhibiting reasonable strength (yield strength $=160 \mathrm{MPa})$, high ductility $(50-60 \%)$ and toughness $\left(>217 \mathrm{MPa} \cdot \mathrm{m}^{1 / 2}\right)[7,8]$. However, the application of this alloy is limited by lack of sufficient high yield and ultimate tensile strength, even though it has high plasticity and toughness. This has been ascribed primarily to single phase microstructure and insufficient lattice distortion[9].

One of the ways to improve strength involves the addition of certain elements in the Cantor alloy to create microstructure providing strengthening of the existing FCC phase. Extensive literature survey reveals that $\mathrm{Al}$ addition to equiatomic $\mathrm{CoCrFeMnNi}$ alloy can definitely affect the microstructural evaluation, providing avenues to design novel microstructures. Previous studies $\mathrm{Al}$ addition on various alloys $\mathrm{TiCoCrFeMn} \mathrm{[10],} \mathrm{CoCrFeNbNi} \mathrm{[11]} \mathrm{as} \mathrm{well}$ as $\mathrm{CoCrFeMnNi}[5]$ categorically show that $\mathrm{Al}$ addition affects the phase formation and microstructural evaluation in these alloys. After being introduced for the first time by Cantor et al.[5], the equiatomic CoCrFeMnNi HEA which is a single phase FCC solid solution [1] has been studied extensively owing to its microstructure[12], thermodynamic stability[13], sluggish diffusion[14], ductility, malleability, low-temperature mechanics[15-17], etc. The 
logic behind the use of $\mathrm{Al}$ as an alloying addition is the dualism of $\mathrm{Al}$ as metal as well as a non-metal which has also led the researchers to use it for the same[18,19]. The cause of this duality is attributed to the special electronic structure of Al. Even though Al has a FCC structure, its effects on the microstructure of HEAs is contrasting. It is reported to promote the formation of hard $\mathrm{BCC}$ crystal structure [20,21]. In addition, $\mathrm{Al}$ addition is required from the perspective of understanding intrinsic lattice distortion in the HEAs. Lattice distortion is considered to be a unique feature in HEAs, controlling deformation micro-mechanism and solid solution strengthening. The lattice distortion, controlling the solid solution strengthening is dictated by relative size difference of atomic species. The atomic size difference is equiatomic CoCrFeMnNi alloy is small, and the effects will not be significant to be proved by experiments. Hence, Al, which has substantially different atomic size, can eventually be incorporated in the Cantor alloy. In order to create sufficiently large lattice distortion, the FCC solid solution must without any solute partitioning. Therefore, careful and optimum level of $\mathrm{Al}$-addition must be maintained to achieve it.

Therefore, it is vital to study the effect of $\mathrm{Al}$ addition to FCC CoCrFeMnNi alloy to understand the above-mentioned aspects. In the present investigation, $\mathrm{Al}_{\mathrm{x}} \mathrm{CrCoFeMnNi}$ alloy with an equiatomic composition of $\mathrm{Cr}, \mathrm{Co}, \mathrm{Fe}, \mathrm{Mn}, \mathrm{Ni}$ and different concentrations of $\mathrm{Al}$ are fabricated via vacuum arc melting under high purity Ar atmosphere on a water cooled copper hearth with-consumable tungsten electrode. The different amount of $\mathrm{Al}$ (0.5 to 10 atom \%) has been added to equiatomic $\mathrm{CoCrFeMnNi}$ alloy via the vacuum arc melting route. The microstructural evaoluation has been probed using XRD, SEM, and TEM. The experimental results have been verified with predictions from CALPHAD to determine the ability and efficiency of thermodynamic modeling for predicting phase evolution in HEA 


\section{Materials and Methods}

\subsection{Samples preparation and characterization}

Alloy buttons with a composition of $(\mathrm{CrCoFeMnNi})_{\mathrm{x}} \mathrm{Al}_{100-\mathrm{x}}(\mathrm{x}=0,0.5,2,3,4,5,6,7,8,10$ atom \%) were synthesized in a vacuum arc melting furnace under high purity Ar atmosphere on a water cooled copper hearth with non-consumable tungsten electrode. The alloy buttons were flipped and re-melted at least five times to ensure chemical homogeneity. Subsequently, the alloys buttons were homogenized sealed in a quartz tube under an argon gas atmosphere and homogenized at $1273 \mathrm{~K}$ for 24 hours, followed by quenching in water. The phase formation and microstructural evolution has been studied using $\mathrm{X}$-ray diffraction $((\mathrm{Cu} \mathrm{K}$ radiation, $\lambda=0.154056 \mathrm{~nm}$ ) using Empyrean Panalytical diffractometer), Scanning electron microscope (SEM, Carl Zeiss, EVO50) equipped with energy dispersive spectroscopy (EDS, Oxford Instruments) and transmission electron microscope (TEM, FEI Tecnai UT20 with accelerating voltage of $200 \mathrm{kV}$ ). The elemental concentration and distribution were determined using EDS analysis.

TEM sample was prepared by cutting the $3 \mathrm{~mm}$ diameter disk from bulk sample followed by dimpling to reduce the thickness in the center of the disk $(40 \mu \mathrm{m})$ and electro-jet polishing using a solution containing $90 \mathrm{vol} . \%$ methanol and $10 \mathrm{vol} . \%$ perchloric acid till perforation in the sample had been made. Hardness measurements were performed on homogenized samples using Tinius-Olsen FH-10 Universal Hardness Testing Machine with a Vickers's Indenter with a load of $5 \mathrm{kgf}$.

\subsection{CALPHAD}


Computational software and databases with recorded thermodynamic values are necessary to use the CALPHAD method to obtain a phase/property diagram which enables us to predict the thermodynamic properties of regions which haven't been experimentally performed. Extrapolation of the binary and ternary systems allows data calculation for higher-order systems. Using the HEA database (TC HEA1 v3.0) the property diagrams of each of the alloy's composition were obtained. Subsequently, the pseudo binary phase diagram was also constructed using the same database. The property diagrams for alloys with $\mathrm{Al}$ concentrations $(0,0.5,4,6$ and 8 at. \%) were constructed to obtain the number of phases present for different samples at a specific temperature.

\section{Results and Discussion}

\subsection{X-Ray Diffraction}

The X-ray diffraction pattern of homogenized samples at $1000{ }^{\circ} \mathrm{C} / 24 \mathrm{~h}$ with different concentration of Aluminium addition $(\mathrm{Al}$ atomic percent $=0,0.5,2,3,4,5,6,7,8,10)$ have been recorded as shown in Figure 1(a). The lattice parameters of the phases have been calculated using precise lattice parameter calculation (Nelson-Riley function)[22] as shown in Figure 1(b). The lattice parameter was significantly increased on the addition of progressively $\mathrm{Al}$ in Cantor alloy and after 7 at. \% it starts to decreases as well as the BCC phase formation observed (shown in Figure 1(b)). The diffractograms of the homogenized samples show the presence of characteristic FCC phase for Cantor's alloy with a lattice parameter of 0.336023 $\mathrm{nm}$. There is a shift in the peaks to the left indicating an increase in lattice parameter for the alloys with $\mathrm{Al}$ concentration up to 6 at.\% indicating continuous lattice expansion with an increase in aluminum content. The pattern corresponding to $6-7$ at. $\%$ Al shows the characteristic FCC 111 peak with a shoulder on the right-hand side, indicating the presence of another phase. In addition, all the peaks of this sample are broader than the peaks of all the alloys containing lower aluminium content. The pattern of samples containing 8 and 10 at.\% 
$\mathrm{Al}$ clearly shows the presence of an additional B2 phase. A weak superlattice 100 peak is also observed in the sample containing 8 at.\% $\mathrm{Al}$ indicating the presence of $\mathrm{B} 2$ phase. It is to be mentioned here that ordering in HEA phases has been reported earlier in the literature[10, 23 27]. It is thus clear that with progressive addition of aluminium up to six atomic percent (Figure 1 a), eqiatomoc CoCrFeMnNi HEA remains single phase albeit undergoing lattice expansion and therefore, increase in lattice distortion. The alloy with 8 at.\% $\mathrm{Al}$ shows a decrease in the lattice constant for the FCC phase and the presence of a B2 phase. There is an increase in the lattice parameter of both the phases for the sample containing 10 at.\% $\mathrm{Al}$.

\subsection{Microstructure and morphology using SEM}

Backscattered electron images (BSE) along with EDS elemental maps showing the elemental distribution of all the alloys have been obtained to show little atomic number contrast for the alloys. The Figures $2 \mathrm{a}(\mathrm{i}-\mathrm{x})$ show the microstructure of the HEAs with the progressively increasing amount of $\mathrm{Al}(0-10$ atom \%). Apparently, there is no perceptible microstructural change have been observed up to 7 at. $\%$ Al. The big black areas are pores formed during casting. There is the same phase contrast observed in these samples. However, some of BSE images $(7$ at.\% $\mathrm{Al})$ reveal the presence of few fine scale precipitates or while phase separation characterized by regions with two distinct contrasts are visible in the samples with 8 and 10 at.\% $\mathrm{Al}$. These results are further corroborated from elemental distribution maps obtained from EDS measurements indicating segregation of $\mathrm{Al}$ for 8 and 10 at.\% Al. Thus it is clear that there is a formation of $\mathrm{BCC} / \mathrm{B} 2$ phase at a higher concentration of aluminum. This can be obtained on the basis of the higher atomic size of aluminum as well as its ambiguous metalloid character that contributes to higher distortion, thereby increasing the entropy of the more open BCC phase compared to close-packed FCC high entropy phase. The segregation of $\mathrm{Al}$ element in the cantor alloys also have been observed using SEM-EDS mapping and shown in Figure 2(b). Al has been observed to be homogeneously distributed in 
the alloy for alloys containing $\mathrm{Al}$ up to 4 at.\% (Fig. 2b(ii)). For HEAs with $\mathrm{Al}$ concentration of 5 at.\% or higher, distinct segregation of $\mathrm{Al}$ has been observed in the homogenized samples (Fig.2b(iii)). For 7 at.\% Al, these Al-segregated zones are distinct and large and hence, can be considered as a separate phase. For alloys with 8 or 10 at.\% Al, a feature of phase separated zones containing ( $\mathrm{Al}, \mathrm{Ni}, \mathrm{Fe}, \mathrm{Cr})$ and $(\mathrm{Mn}, \mathrm{Ni})$ are evident. Hence, $\mathrm{Al}$ maps, obtained by $\mathrm{EDS}$ measurements clearly suggests the stability and new phase formation in the Al-containing HEAs.

\subsection{Transmission Electron Microscopic (TEM) analysis}

The finer scale microstructural characterization of anll the Al-containing samples have been carried out to understand the formation of different phases, size, and their morphologies. However, we shall discuss here the salient results. The Figures 3(a-d) shows the bright field image of the equiatomic CoCrFeMnNi alloy as well as HEAs with different $\mathrm{Al}$ concentration. Figure 3a reveals large grains $(1-5 \mu \mathrm{m})$ single phase FCC phase in the equiatomic $\mathrm{CoCrFeMnNi}$ with inset showing selected area pattern from one such grain. Similar features have been observed for $\mathrm{Al}=0.5$ (Fig. 3b) and 5 at.\% $\mathrm{Al}$ ( Fig. 3c). In fact, single phase FCC grains have been observed for HEAs containing 6 at.\% Al. Figure 3d shows a bright field image of 8 at.\% $\mathrm{Al}$, revealing the second phase as circular precipitation and corresponding ring diffraction pattern confirmed the $\mathrm{BCC}$ second phase formation. Therefore, it is evident that $\mathrm{BCC} / \mathrm{B} 2$ precipitates form for alloys containing $\mathrm{Al}$ up to 7 at.\% or higher.

In order to corroborate the experimental findings, thermodynamic modeling was carried out using CALculation of PHAse Diagram approach using CALPHAD software with TCHEA 3 database. The results of these calculations have been provided in terms of property diagram as well as a pseudobinary phase diagram. Figures $4(\mathrm{a}-\mathrm{e})$ show the property diagram with varying concentration of $\mathrm{Al}(0,0.5,4,6$ and 8 at.\%) whereas Fig. $4 \mathrm{f}$ reveals the pseudobinary 
phase diagram obtained by varying $\mathrm{Al}$ concentration in the $(\mathrm{CoCrFeMnNi})_{100-\mathrm{x}} \mathrm{Al}_{\mathrm{x}} \mathrm{HEAs}$. The property diagrams reveal that for a lower concentration of $\mathrm{Al}$ ( $\mathrm{x} \leq 3$ at.\%), $\mathrm{FCC}$ phase remains stable in the large temperature range $\left(800-1250^{\circ} \mathrm{C}\right)$. At lower temperature, sigma phase is stable along with FCC HEA phase. However, alloy with 4 at.\% $\mathrm{Al}$ and above, BCC/B2 phases appear. It is evident two BCC/B2 phases (AlNi-rich and $\mathrm{AlFeCr}$-rich ) can form in the temperature range of 1050 to $500^{\circ} \mathrm{C}$. For higher concentration of $\mathrm{Al}(6,8$ and 10 at.\%), a fraction of $\mathrm{BCC} / \mathrm{B} 2$ phases increase substantially and with 10 t. $\% \mathrm{Al}, \mathrm{BCC} / \mathrm{B} 2$ phase becomes the major phase. The microstructural observations indicate similar features. The presence of FCC HEA phase for alloy having $\mathrm{Al}$ up to 6 at.\% is evident whereas $\mathrm{BCC} / \mathrm{B} 2$ phase has observed for the alloy with $\mathrm{Al}$ concentration of 7 at.\% of higher. Accordingly, a pseudobinary phase diagram has been generated using HEA3 data base in CALPHAD. It has been observed that the phase diagram shows a FCC phase field, which shrinks with an increase in aluminium content. However, the compositional range of stability of the FCC phase seems to be small as compared to the experimental observations. BCC/B2 phase field overlaps with FCC HEA phase, indicating it is possible to have coexistence of this two phase in the microstructure. Another important observation is the presence of sigma phase and a BCC and B2 phase in all the phase diagrams for compositions from 0.5 percent and higher aluminium content. It is observed that there is a decrease in the fraction of the FCC phase at the expense of the BCC phase for all the compositions containing aluminium while at higher aluminium concentrations, the B2 phase region increases at the expense of the Sigma phase region. The pseudo-binary diagram of the Cantors alloy and aluminium shows the presence of liquid phase and solid FCC and B2 phase till ten atomic percent aluminium.

\subsection{Hardness Measurements}


In order to probe the effect of $\mathrm{Al}$ addition on the mechanical property, the hardness of the homogenized samples has been measured and reported in Figure 5. It shows that hardness monotonically increases up to 6 at.\% $\mathrm{Al}$ and this is followed by a rapid increase of increase up to 10 at.\% $\mathrm{Al}$. The first increase may be assigned to solutelid solution hardening where as the later part (as marked on the Fig.5) is due to the formation of B2 precipitates in the FCC matrix. Hence, Al- addition causes hardness change due to two distinct mechanisms. In the former, the solid solution hardening and associated lattice distortion in the multielemental matrix because of distinctly smaller atomic diameter as compared to other elements ( $\mathrm{Co}, \mathrm{Cr}$, $\mathrm{Fe}, \mathrm{Mn}$, and $\mathrm{Ni}$ ). It has been shown earlier that HEAs are characterized by higher lattice distortion compared to conventional metals and alloys. This leads to pinning of dislocations by a local solute environment that contributes to higher lattice friction stress. It is expected that a significantly larger aluminum atom in the $\mathrm{CoCrFeMnNi}$ solid solution will cause significant lattice distortion and contribute to higher friction stress thereby contributing to an increase in hardness. It is to be mentioned here that other contributions to hardness or strength from different strengthening mechanisms like Hall-Petch hardening, hardening from dislocations and twins are also to be monitored for deconvoluting the contribution from solid solution hardening. Theoretical analysis of the atomic radii clearly shows an increase in atomic size difference parameter as well as lattice mismatch parameter with the addition of aluminium clearly indicating an increase in lattice distortion with aluminium content. Further analysis by determining the width to Burgers ratio for the Cantors alloy and the alloys containing 4, 6 and 7 weight percent aluminium show a continuous decrease in w/b ratio with aluminium addition. The lower value of $\mathrm{w} / \mathrm{b}$ ratio indicates that the core of the dislocation is constricted and hence the Peierls-Nabarro stress required for movement of dislocation that scales inversely with the exponential of w/b ratio continuously increases with increasing aluminium content. 
$\tau_{P-N}=G^{*} e^{-(2 \pi w / b)}$, where, $\mathrm{w}$ is the dislocation width, $\mathrm{b}$ is Burgers vector, and $\tau_{\mathrm{P}-\mathrm{N}}$ is Peierls-Nabarro stress

There is a decrease in the shear modulus with an increase in aluminum content but the decrease in dislocation constriction factor $\mathrm{w} / \mathrm{b}$ compensates for the decrease in decrease in shear modulus, and there is an increase in Peierls-Nabarro stress with an increase in aluminium content. Therefore, it can be concluded that aluminium addition in Cantors alloy till seven atomic percent contributes to higher lattice distortion that causes constriction of the core of the dislocation, thereby making dislocation motion more difficult. A continuous increase in lattice distortion parameter and lattice mismatch strain parameter accompanied with a continuous decrease in $\mathrm{w} / \mathrm{b}$ ratio clearly indicate an increase in lattice distortion with aluminium addition which contributes to increasing in hardness.

\section{Summary and conclusions}

The present study has shown that $\mathrm{Al}$ addition to equiatomic CoCrFEMnNi HEA affects the phase formation and microstructural evolution significantly and according to the mechanical properties can be tuned by adding a different amount of $\mathrm{Al}$ to the alloys. The following conclusions can be drawn from the study:

1. FCC HEA phase in the Cantor is stable up to 6 at.\% of $\mathrm{Al}$ addition. $\mathrm{Al}$ can dissolve in the FCC phase and expand the lattice causing lattice distortion.

2. For the higher amount of $\mathrm{Al}(6-10$ at. $\%),(\mathrm{Al}, \mathrm{Ni}, \mathrm{Fe})$-rich $\mathrm{BCC} / \mathrm{B} 2$ phase precipitates in the FCC matrix. The precipitates show near spherical shape with nanometric size.

3. Thermodynamical calculations using HEA3 database reveal that FCC HEA phase is stable at a higher temperature $\left(800-1250_{-}^{0} \mathrm{C}\right)$ in the Cantor alloy as well as with low 
Al-content (3 at.\%), and higher amount of Al-addition (4 at.\% and higher) leads to the formation of $\mathrm{BCC} / \mathrm{B} 2$ phases. Although the sigma phase is reported in the property diagrams, its presence was not detected in the homogenized samples.

4. Hardness measurements indicate distinct and monotonous increase up to 6 at $\% \mathrm{Al}$, which can be ascribed due to lattice distortion due to $\mathrm{Al}$ addition. $\mathrm{Al}$ atom, being smaller in size can lead to severe lattice distortion and hence increase in hardness. For higher $\mathrm{Al}$ content (7 at.\% and higher), $\mathrm{BCC} / \mathrm{B} 2$ precipitates lead to a rapid increase in the hardness, which can be explained as hardening due to precipitation.

In a nutshell, $\mathrm{Al}$ can be added to equiatomic CoCrFEMnNi HEA to tune the mechanical properties by both controlling lattice distortion as well as precipitation of secondary phase in the FCC HEA matrix and hence, it opens up new vistas of novel microstructural design and understand the lattice distortion in the HEA. 


\section{References}

[1] Murty BS, Yeh JW, Ranganathan S. Chapter 1 - A Brief History of Alloys and the Birth of HighEntropy Alloys. High Entropy Alloys. Boston: Butterworth-Heinemann; 2014. p. 1-12.

[2] Miracle DB, Senkov ON. Acta mater, 122 (2017):448-511.

[3] Reddy TS, Wani IS, Bhattacharjee T, Reddy SR, Saha R, Bhattacharjee PP. Intermetallics, 91 (2017):150-7.

[4] Wani IS, Sathiaraj GD, Ahmed MZ, Reddy SR, Bhattacharjee PP. Mater Charact,118 (2016):417-24.

[5] Cantor B, Chang ITH, Knight P, Vincent AJB. Mater Sci Eng A, 375-377 (2004):213-8.

[6] Cantor B. Entropy, 16 (2014):4749-68.

[7] Yeh JW. Ann Chim - Sci Mat,31 (2006):633-48.

[8] Kumar N, Tiwary CS, Biswas K. J Mater Sci, (2018).

[9] Zhao YY, Nieh TG. Intermetallics, 86 (2017):45-50.

[10] He JY, Liu WH, Wang H, Wu Y, Liu XJ, Nieh TG, et al. Acta mater, 62 (2014):105-13.

[11] Sun X, Zhang H, Lu S, Ding X, Wang Y, Vitos L. Acta mater, 140 (2017):366-74.

[12] Otto F, Dlouhý A, Somsen C, Bei H, Eggeler G, George EP. Acta mater,61 (2013):5743-55.

[13] Schuh B, Mendez-Martin F, Völker B, George EP, Clemens H, Pippan R, et al. Acta mater, 96 (2015):258-68.

[14] Tsai KY, Tsai MH, Yeh JW. Acta mater, 61 (2013):4887-97.

[15] Stepanov N, Tikhonovsky M, Yurchenko N, Zyabkin D, Klimova M, Zherebtsov S, et al. Intermetallics, 59 (2015):8-17.

[16] Liu TK, Wu Z, Stoica AD, Xie Q, Wu W, Gao YF, et al. Mater Des, 131 (2017):419-27.

[17] Moon J, Bae JW, Jang MJ, Baek SM, Yim D, Lee B-J, et al. Mater Chem Phys, 210 (2018):187-91.

[18] Li C, Li JC, Zhao M, Jiang Q. J Alloys Compd, 504 (2010):S515-S8.

[19] Li C, Li JC, Zhao M, Jiang Q. J Alloys Compd,475 (2009):752-7.

[20] Varalakshmi S, Kamaraj M, Murty BS. J Alloys Compd, 460 (2008):253-7.

[21] Wang WR, Wang WL, Wang SC, Tsai YC, Lai CH, Yeh JW. Intermetallics, 26 (2012):44-51.

[22] Nelson JB, Riley DP. Proceedings of the Physical Society, 57 (1945):160-77.

[23] Biswas K, Phanikumar G, Holland-Moritz D, Herlach DM, Chattopadhyay K. Philosophical Magazine,87 (2007):3817-37.

[24] Biswas K, Phanikumar G, Chattopadhyay K, Volkmann T, Funke O, Holland-Moritz D, et al. Mater Sci Eng A,375-377 (2004):464-7.

[25] Mridha S, Samal S, Khan PY, Biswas K, Govind. Metall Mater Trans A, 44 (2013):4532-41.

[26] Mohanty S, Maity TN, Mukhopadhyay S, Sarkar S, Gurao NP, Bhowmick S, et al. Mater Sci Eng A,679 (2017):299-313.

[27] Mishra A, Samal S, Biswas K. Trans Indian Inst Met, 65 (2012):725-30.

\section{Figures}




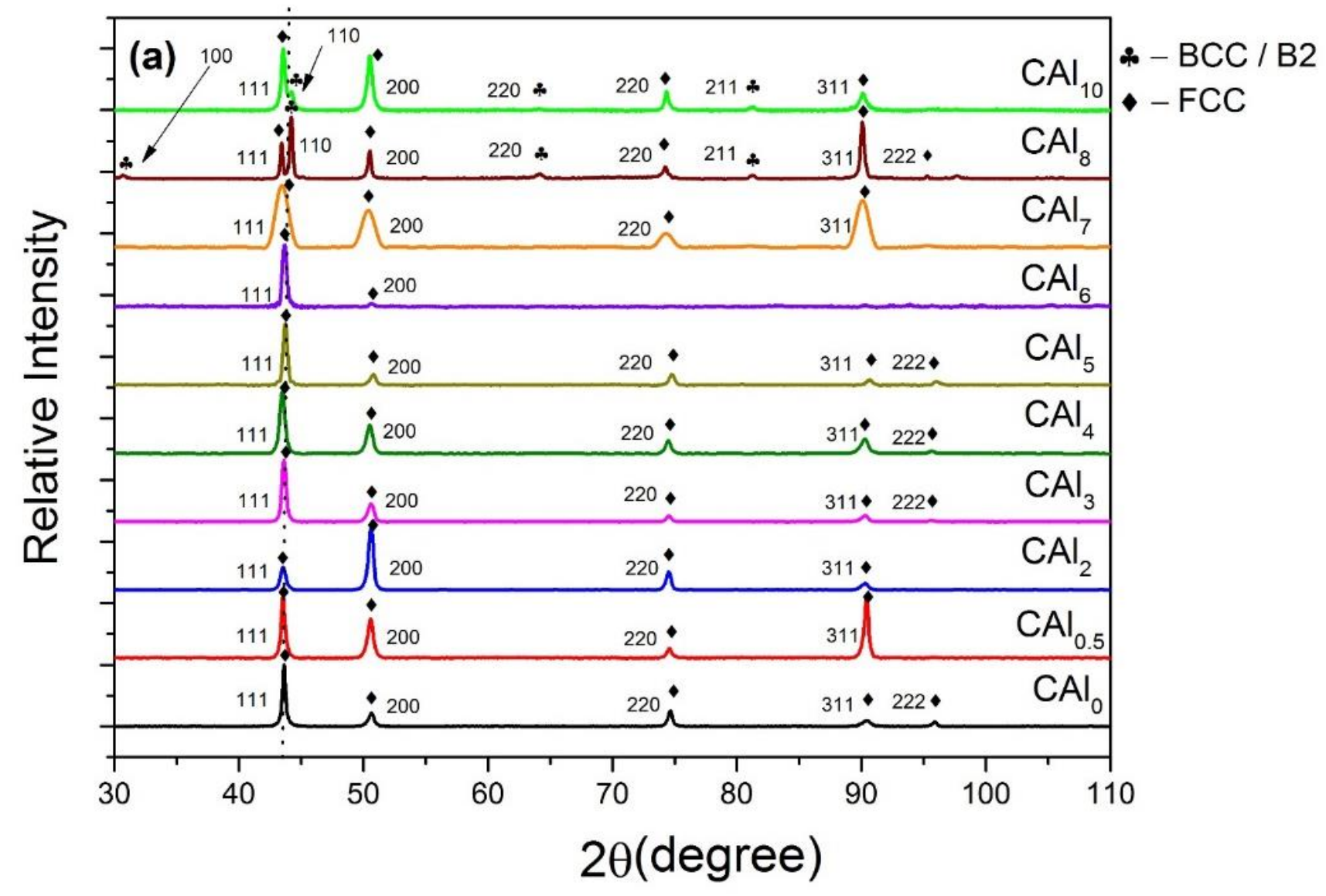




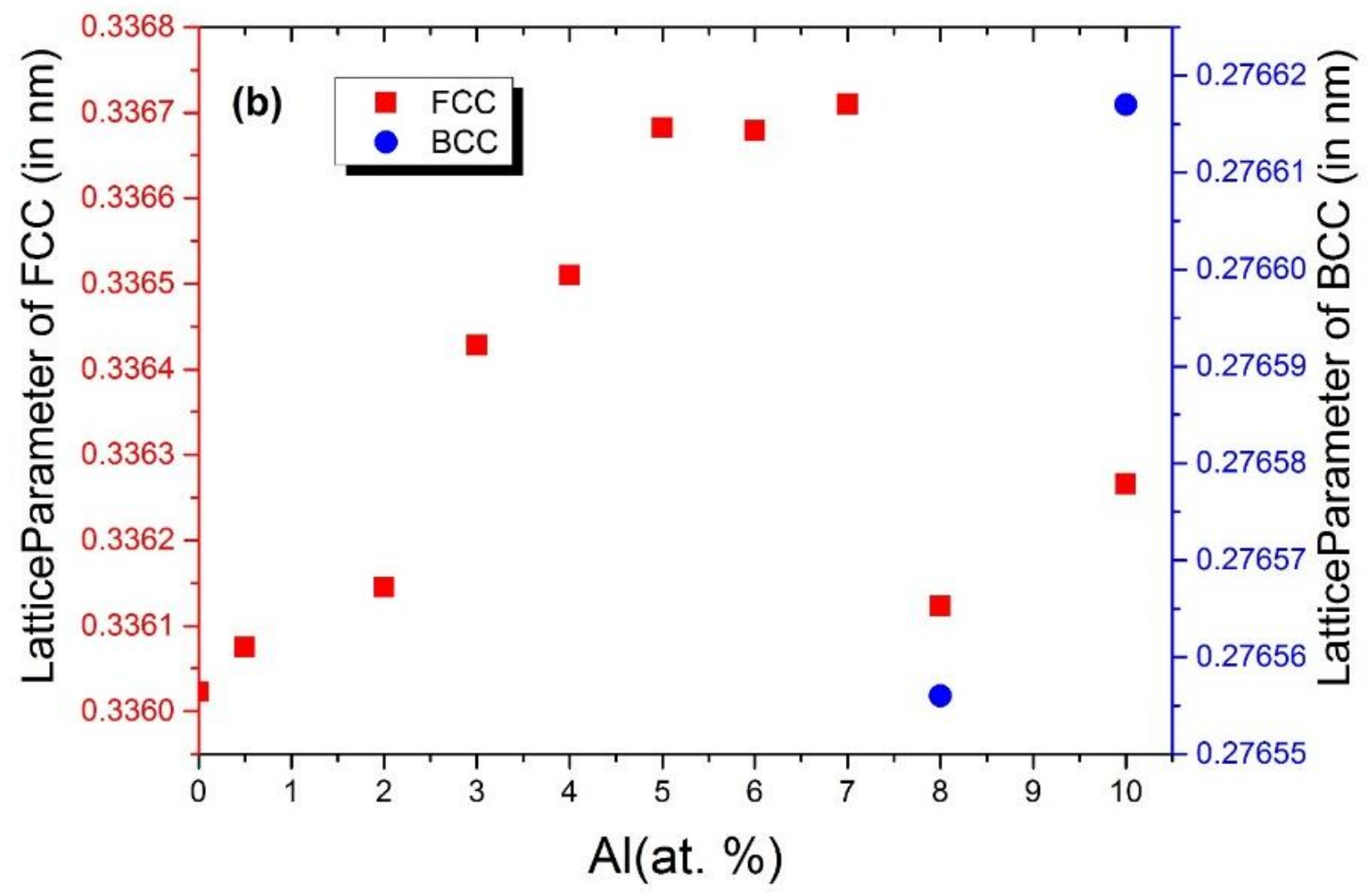


Figure 1: (a). XRD patterns of homogenised samples of $C A I_{x}$, where $C A I_{x}$ is $(\mathrm{CrCoFeMnNi})_{100-\mathrm{x}} \mathrm{Al}$ x where $\mathrm{x}$ (at. \%) varies as $0,0.5,2,3,4,5,6,7,8,10$;

(b).Lattice parameters of FCC (represented by squares) and BCC (represented by circles) of $(\mathrm{CoCrFeMnNi})_{100-\mathrm{x}} \mathrm{Al}_{\mathrm{x}}$ alloys as a function of at.\% of $\mathrm{Al}$. 

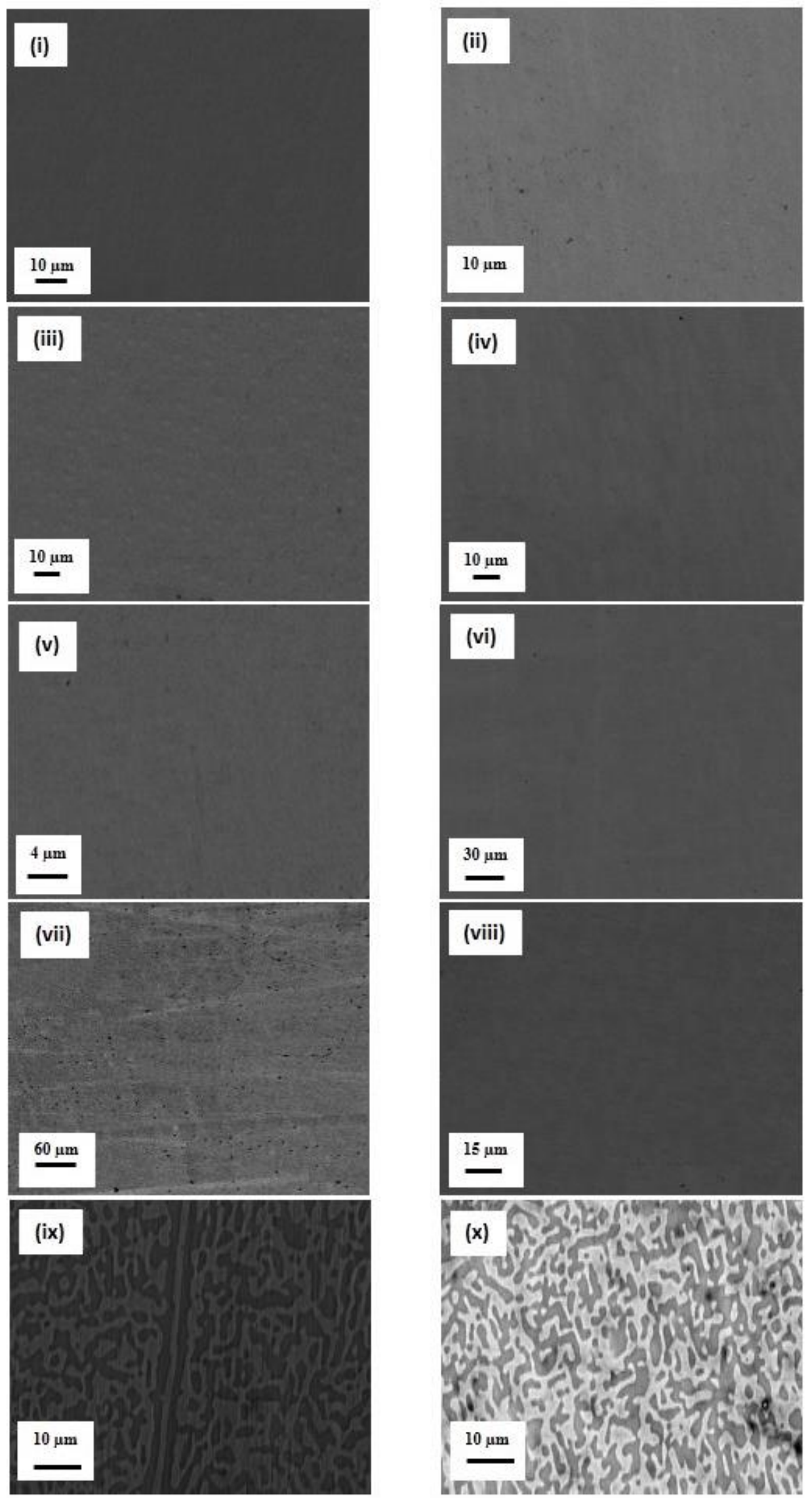

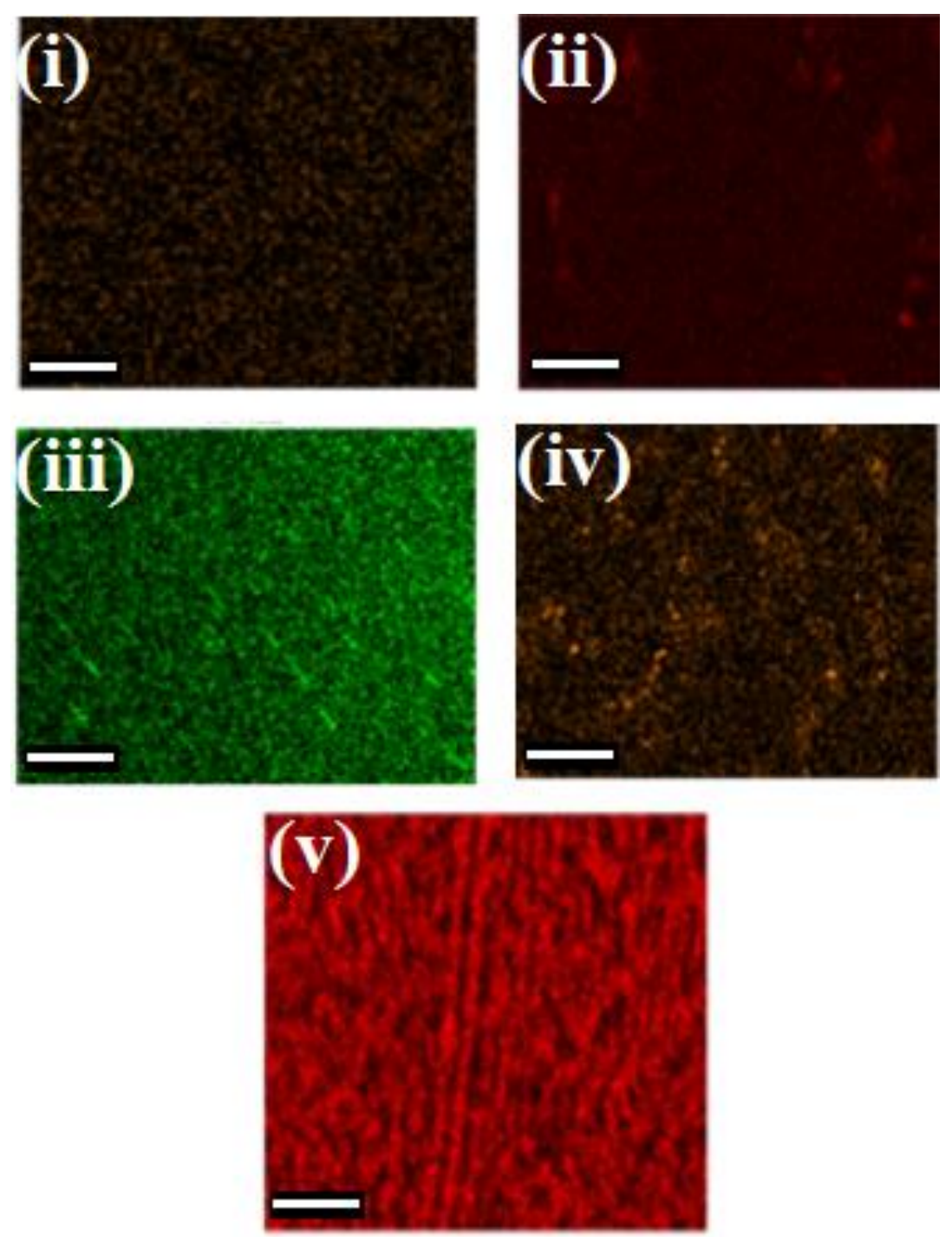

Figure 2 : (a) SEM backscattered electron micrographs of the homogenized (CoCrFeMnNi) ${ }_{100-\mathrm{x}} \mathrm{Al}_{\mathrm{x}}$ where $\mathrm{x}$ (at. \%) varies as: (i) 0,(ii) 0.5, (iii) 2, (iv) 3, (v) 4, (vi) 5, (vii) 6, (viii) 7,(ix)8, (x)10;(b).EDS mappingshowing $\mathrm{Al}$ distribution in the homogenised (CoCrFeMnNi) ${ }_{100}$ ${ }_{x} \mathrm{Al}_{\mathrm{x}}$ where $\mathrm{x}$ (at. \%) varies as: (i) 0.5, (ii) 4, (iii) 5, (iv) 7, (v) 8. (Scale bar in all image is $25 \mu \mathrm{m}$ ) 

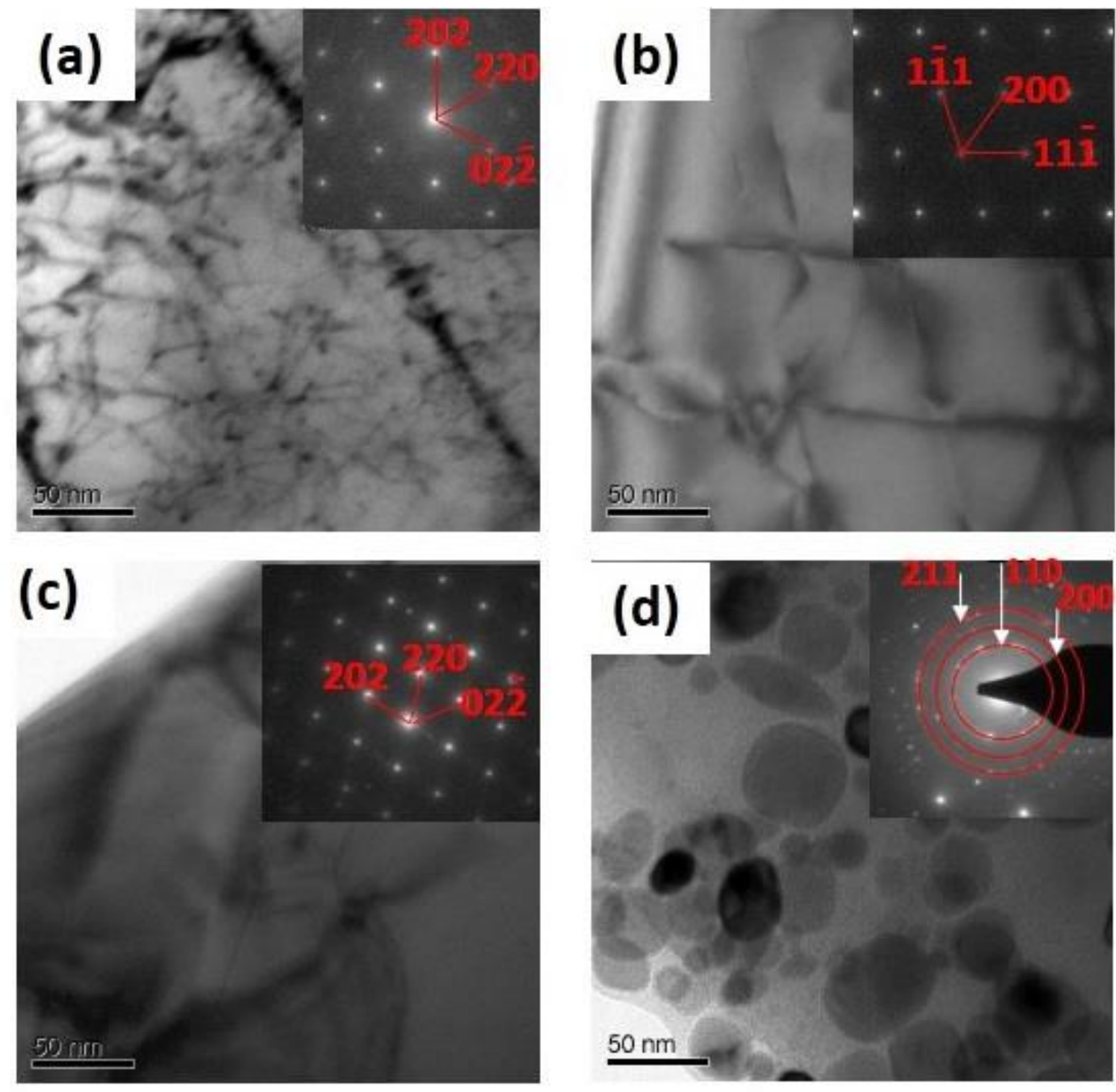

Figure 3. TEM bright field micrograph, inset shows corresponding diffraction pattern(a) 0 at $\% \mathrm{Al}$ (b) 0.5 at $\% \mathrm{Al}$ (c) 5 at $\% \mathrm{Al}$ (d) 8 at $\% \mathrm{Al}$ 

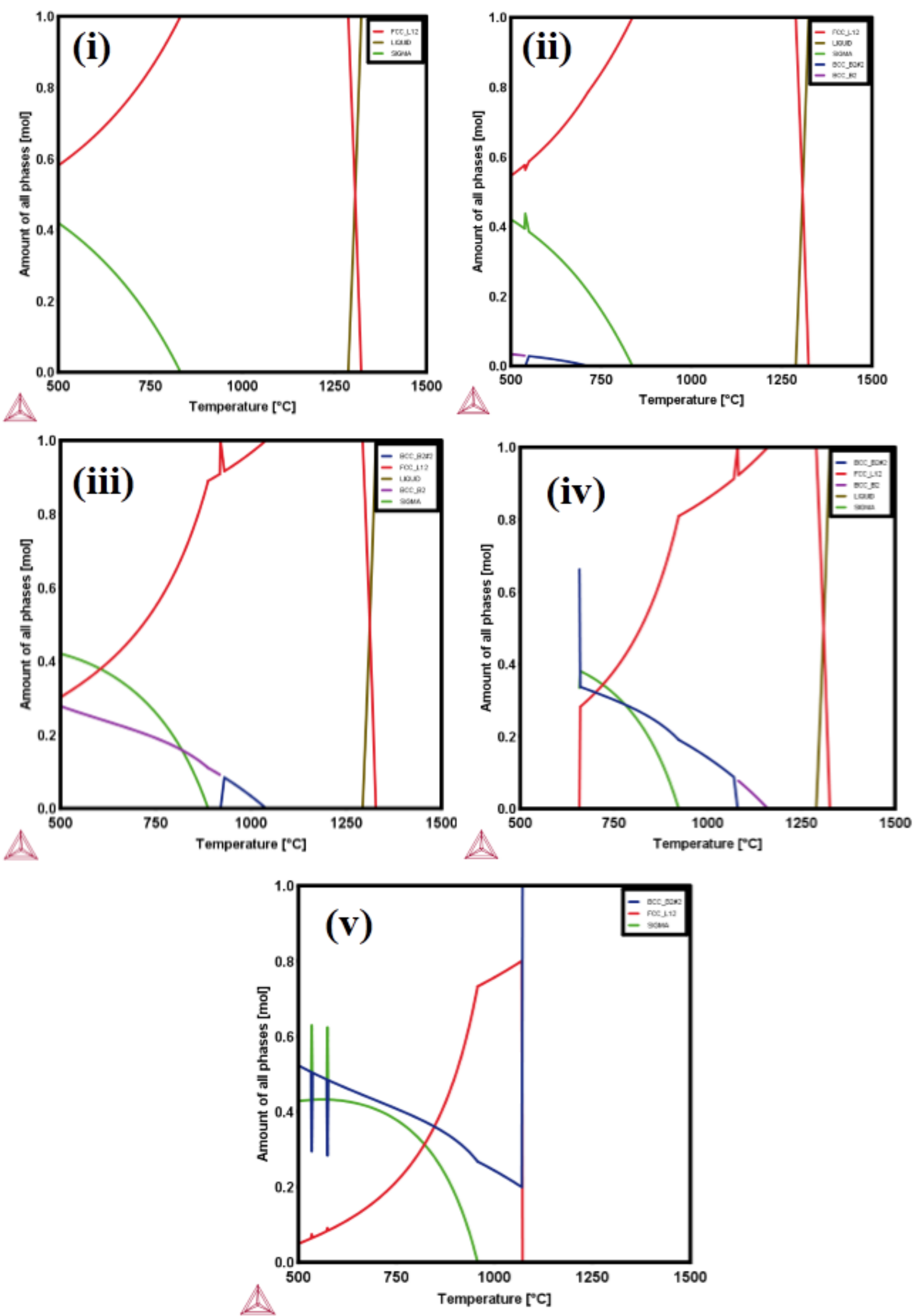

(a) 


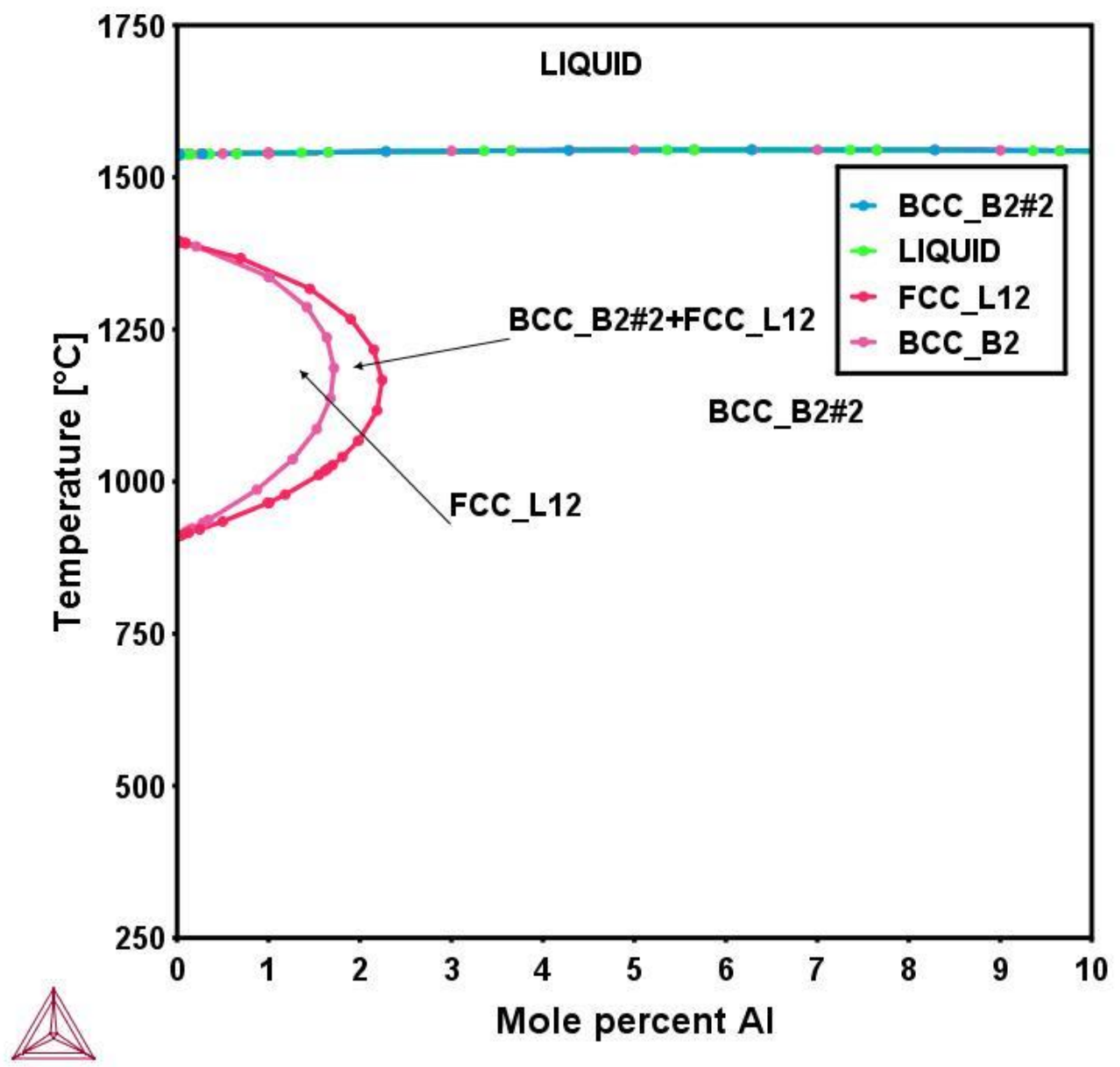

\section{(b)}

Figure 4 :(a) Property diagrams of $(\mathrm{CoCrFeMnNi})_{100-\mathrm{x}} \mathrm{Al}_{\mathrm{x}}$ where $\mathrm{x}$ (at. \%) is: (i) 0 , (ii) 0.5 , (iii) 4, (iv) 6, (v) 8; (b) pseudo Binary Phase diagram of $(\mathrm{CoCrFeMnNi})_{100-\mathrm{x}} \mathrm{Al}_{\mathrm{x}}(\mathrm{x}=0,0.5,2,3,4,5,6,7,8,10)$ 


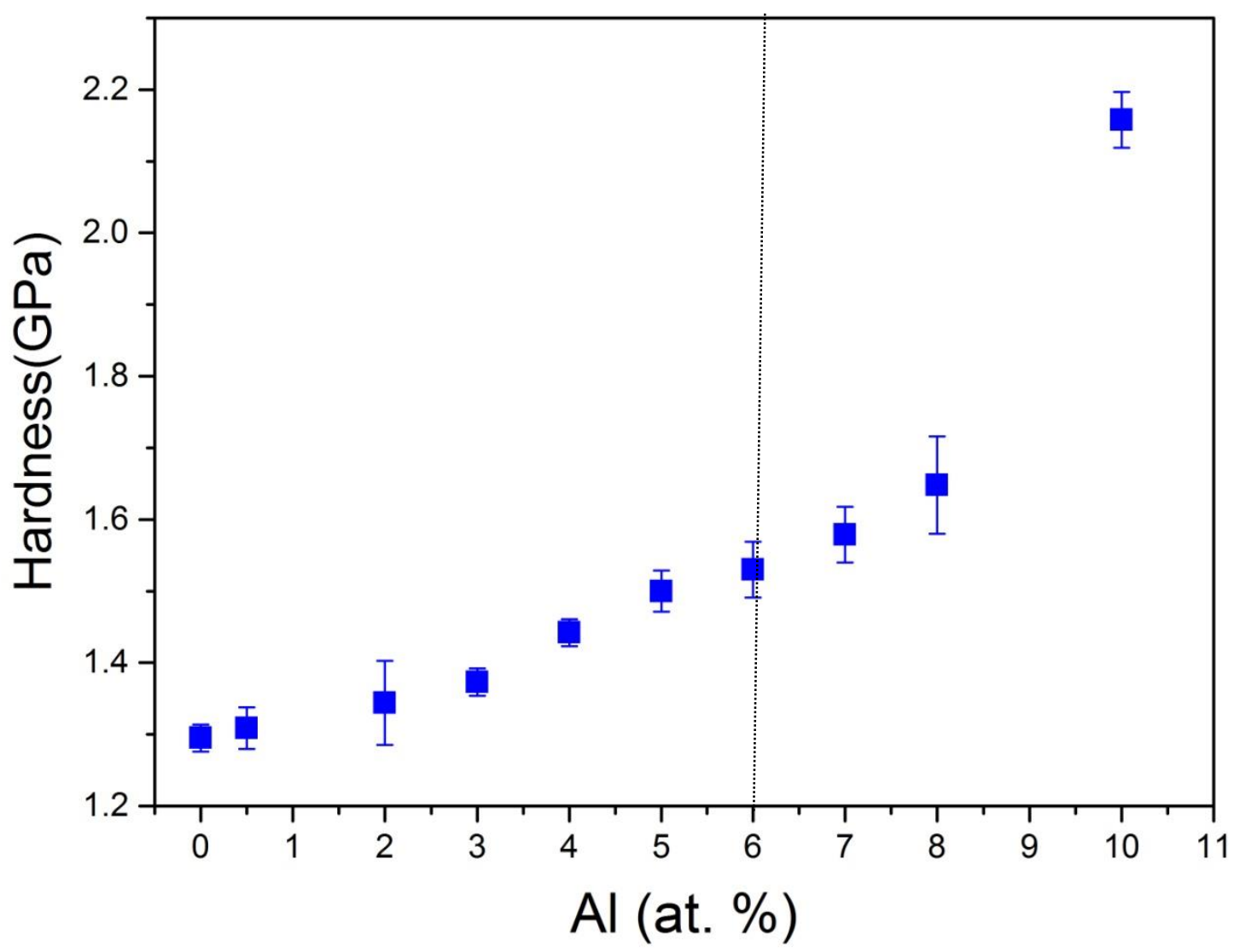

Figure 5. Vickers hardness variation with $\mathrm{Al}$ content 